UDC 629.7.058

DOI: http://dx.doi.org/10.20535/2219-3804192018169621

O. Zbrutsky ${ }^{\mathbf{1}}$, professor, O. Kizitsky $^{2}$, student, A. Kornienko ${ }^{3}$, student

\title{
THE MULTICOPTER AUTOMATIC CONTROL SYSTEM WITH THE GUARANTEED ACCURACY
}

Ua Запропоновано алгоритм та розроблена структурна схема системи автоматичного керування кутовим рухом мультикоптера для забезпечення попередньо заданої точності керування в умовах невизначених зовнішніх збурень. Моделюванням показана ефективність алгоритму.

$\mathbf{R u}$ Предложен алгоритм и разработана структурная схема системы автоматического управления угловым движением мультикоптера для обеспечения предварительно заданной точности управления в условиях неопределенных внешних возмущений. Моделированием показана эффективностьалгоритма.

\section{Introduction}

Modern systems of guaranteed accuracy $[1, \ldots, 4]$ are difficult to implement. Adaptive algorithms that use methods for evaluating active perturbation with its known characteristics are discussed in [3]. Adaptive algorithms for ensuring the guaranteed accuracy of the control system, in which the external perturbation action is evaluated by the variables of the system state, are discussed in [4]. Adaptive algorithms that provide guaranteed stability of the stabilization, are proposed in $[5,6]$, but the criteria for the regulator gain constructing are not disclosed.

Multicopter aircraft is becoming increasingly popular due to their simplicity of design. In the majority of existing multicopter automatic control systems the standard proportional-integral-differential (PID) regulators are used. The issue of ensuring the accuracy of such control systems is not considered.

Since the multicopter moves in a horizontal plane only with the required inclination of the body, it is important to accurately maintain the program inclination and reduce the external perturbations.

\section{Problem formulation}

The purpose of the article is to develop a control law for the angular position of a multicopter, which must provide a given accuracy of the aircraft angular position during its stabilization or program control incases of uncertain nature and magnitude of external perturbations.

\footnotetext{
${ }^{1}$ Igor Sikorsky Kyiv Polytechnic Institute,

${ }^{2}$ Igor Sikorsky Kyiv Polytechnic Institute,

${ }^{3}$ Lion Centrsl School, France
} 


\section{Synthesis of the feedback regulator}

The feedback is implemented as the PID - controller in the form shown in fig. 1 to provide the control systemastatism, where $F$ is the frame of the multicopter, $E$ indicates motors, $M$ is the moment of external perturbation, $k_{p}, k_{d}, k_{i}$ are the coefficients of the proportional, differentiating and integrated links of the PID - controller, $\alpha_{c}$ is the control signal, $\alpha$ is the multicopter angle of inclination.

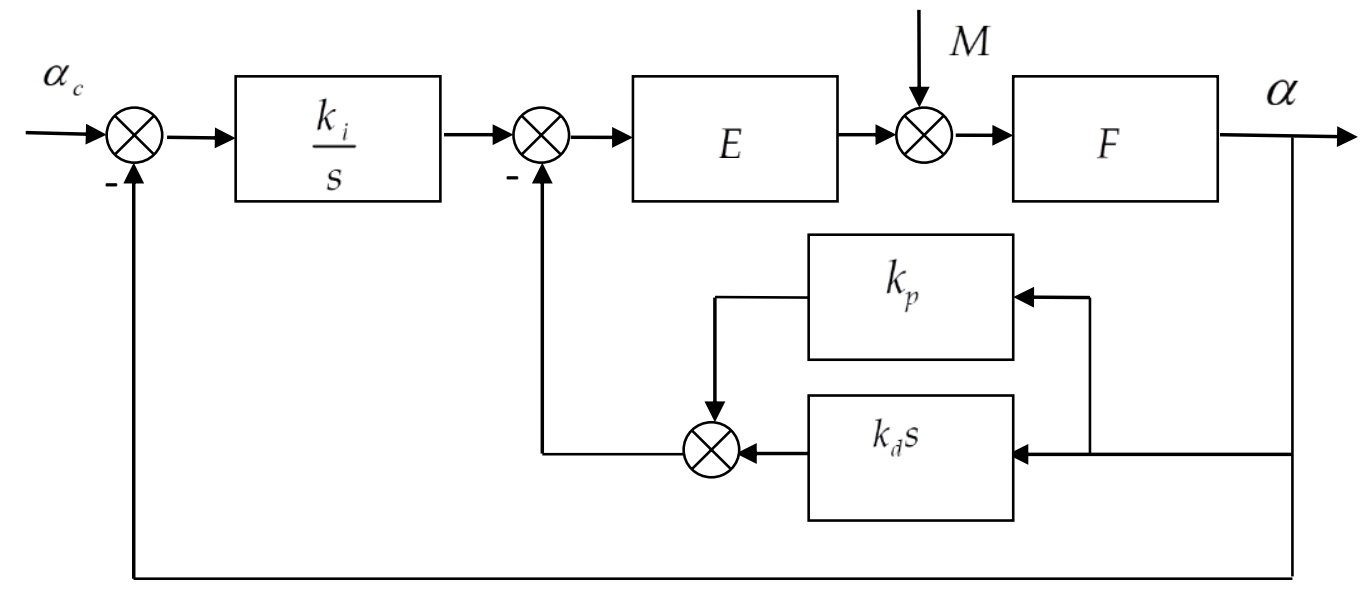

Fig. 1. Angle position control system

The transfer functions of the multicopter elements will be taken in the form

$$
W_{F}=\frac{k_{F}}{I s^{2}+f s+k_{m}}, W_{E}=\frac{k_{e}}{T_{e} s+1},
$$

where $I, f, k_{m}, k_{F}$ are the moment of inertia, the coefficient of resistance, the pendulum coefficient and the constructive parameter of the multicopter, $k_{e}, T_{e}$ is the transmission coefficient and the time constant of the engine.

Synthesis of the control system is carried out by the method of standard transient characteristics [7] by minimizing the functional $I=\int_{0}^{\infty} t|e(t)| d t$, which gives the system optimal characteristic polynomial in the form

$$
s^{3}+1,75 \omega_{0} s^{2}+2,15 \omega_{0}^{2} s+\omega_{0}^{3},
$$

Given the small size of $T_{e} I$, the system transferable functions by control and perturbation will look 


$$
\begin{aligned}
& W_{\alpha c}^{\alpha}=\frac{k_{e} k_{i} k_{F}}{\left(T_{e} f+I\right) s^{3}+\left(T_{e} k_{m}+f+k_{d}\right) s^{2}+\left(k_{m}+k_{e} k_{p} k_{F}\right) s+k_{e} k_{i} k_{F}}, \\
& W_{M}^{\alpha}=\frac{\left(T_{e} s+I\right) k_{F} s}{\left(T_{e} f+I\right) s^{3}+\left(T_{e} k_{m}+f+k_{d}\right) s^{2}+\left(k_{m}+k_{e} k_{p} k_{F}\right) s+k_{e} k_{i} k_{F}} .
\end{aligned}
$$

The choice of coefficients of the PID regulator is carried out according to the known parameters of the multicopter (1) and the necessary parameters of the transition process in accordance with the optimal polynomial (2).

The result of simulation the system reaction to the control signal $\alpha_{c}=20$ deg, shown in fig. 2 , meets the pre-set requirements. The results of simulation the system reaction to perturbations are shown in fig. 3 (perturbation $0,1 \cdot N \times m$ $0,1 \cdot N \times m$ (curve 1), $0,2 \cdot N \times m$ (curve 2) and $0,3 \cdot N \times m$ (curve 3 )) and reflect the directly proportional dependence of the reaction value on the perturbation value.

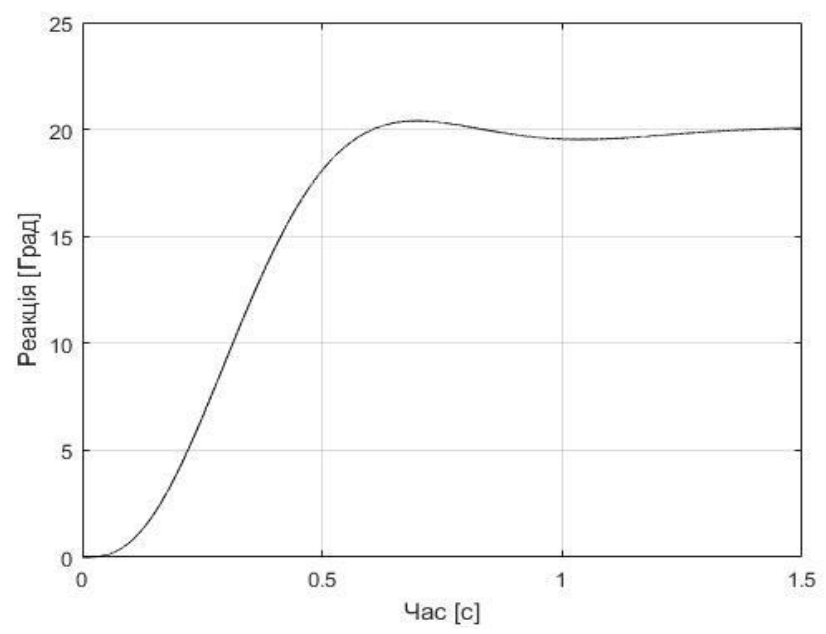

Fig. 2. System reaction to control

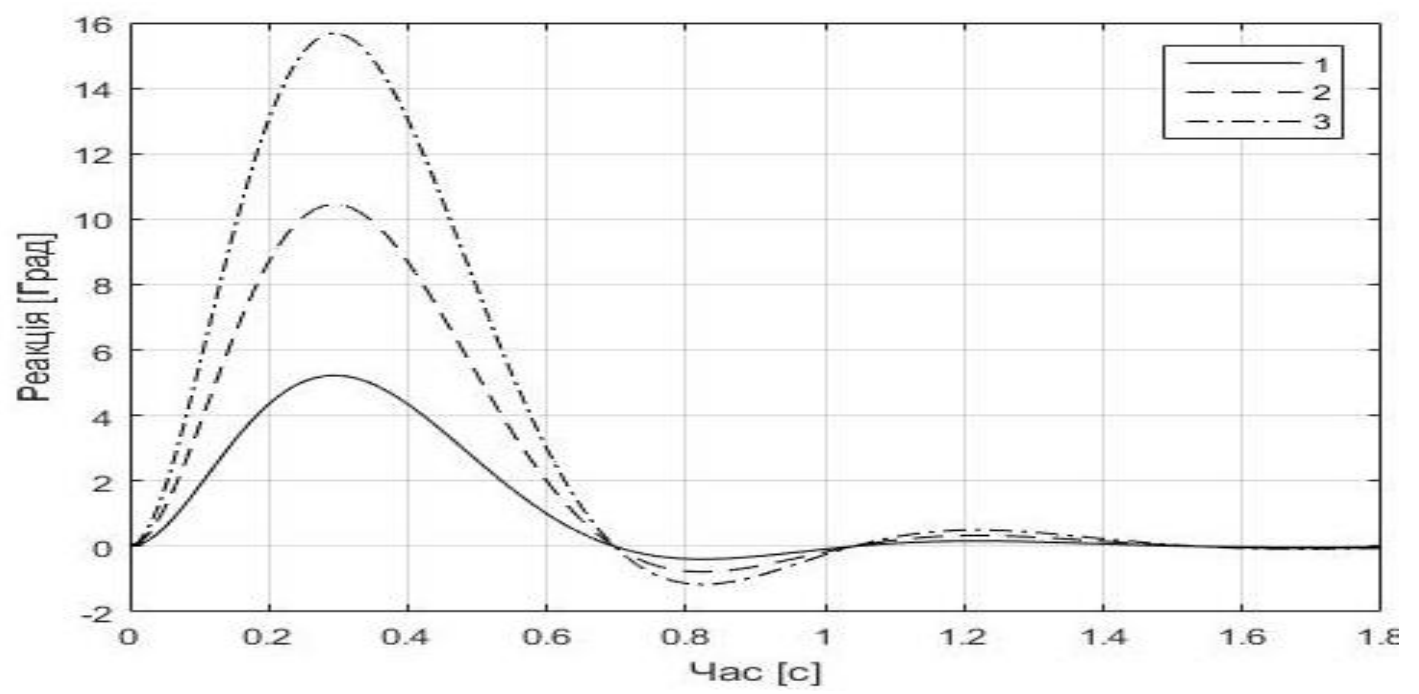

Fig. 3. System reaction to perturbation 


\section{Guaranteed accuracy control system}

Convert the structural scheme of the system (fig. 1) to the form shown in fig. 4 .

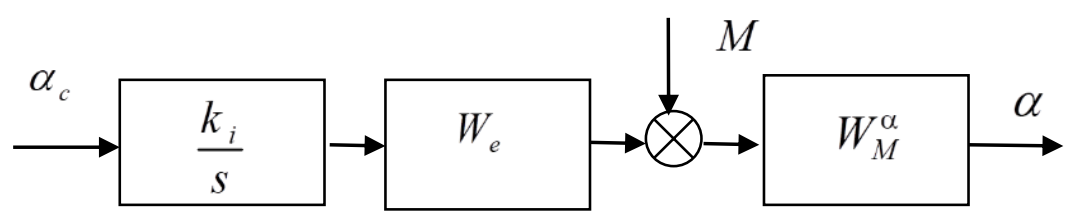

Fig. 4. Control system

The method of the reverse dynamic model [4, 5] for the control guaranteed accuracy implementation in the case of perturbations is used. An additional $K W_{c}$ controller (fig. 5), in which the coefficient $K$ is a function of the angle $\alpha$ of multicopter deviation from a given position, is introduced.

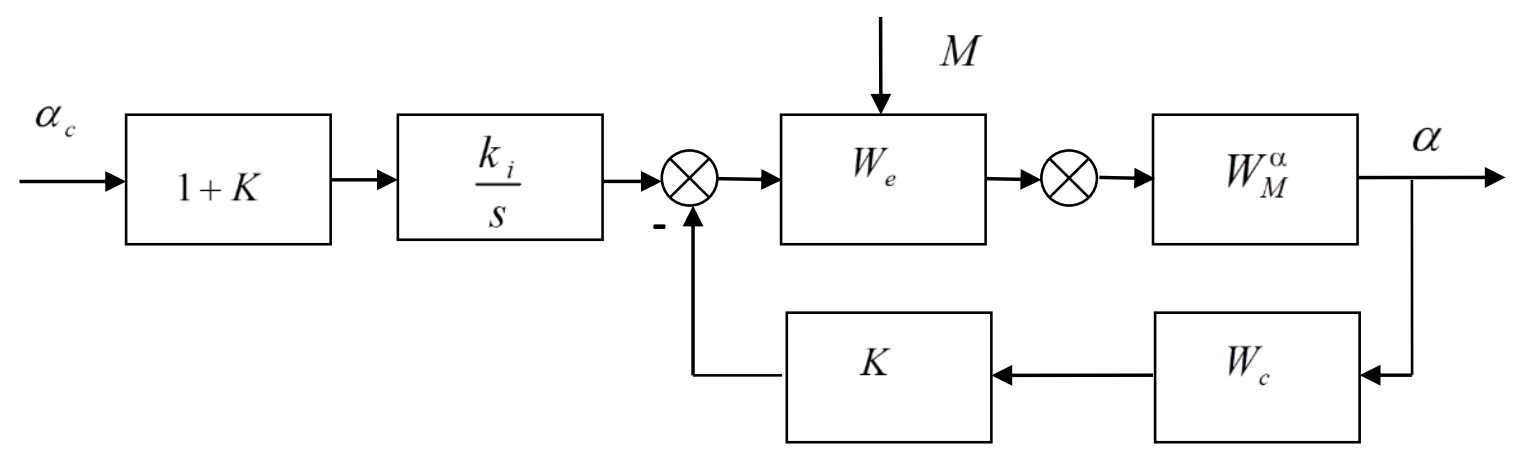

Fig. 5. Control system with an additional regulator

Neglecting $T_{e}$, we receive

$$
W_{c}=\frac{I s^{3}+\left(f+k_{d}\right) s^{2}+\left(k_{m}+k_{e} k_{p} k_{F}\right) s+k_{e} k_{i} k_{F}}{k_{F} k_{e} s} .
$$

The transfer function (5) corresponds to the PID - regulator. Transfer functions of the system on perturbation and control will be:

$$
W_{1 M}^{\alpha}=\frac{W_{M}^{\alpha}}{1+K}, \quad W_{1 c}^{\alpha}=W_{\alpha c}^{\alpha}
$$

and the structural scheme can be converted to the form shown in fig. 6 , where

$$
W_{1 c}=W_{c}-\frac{k_{i}}{s} \text {. }
$$




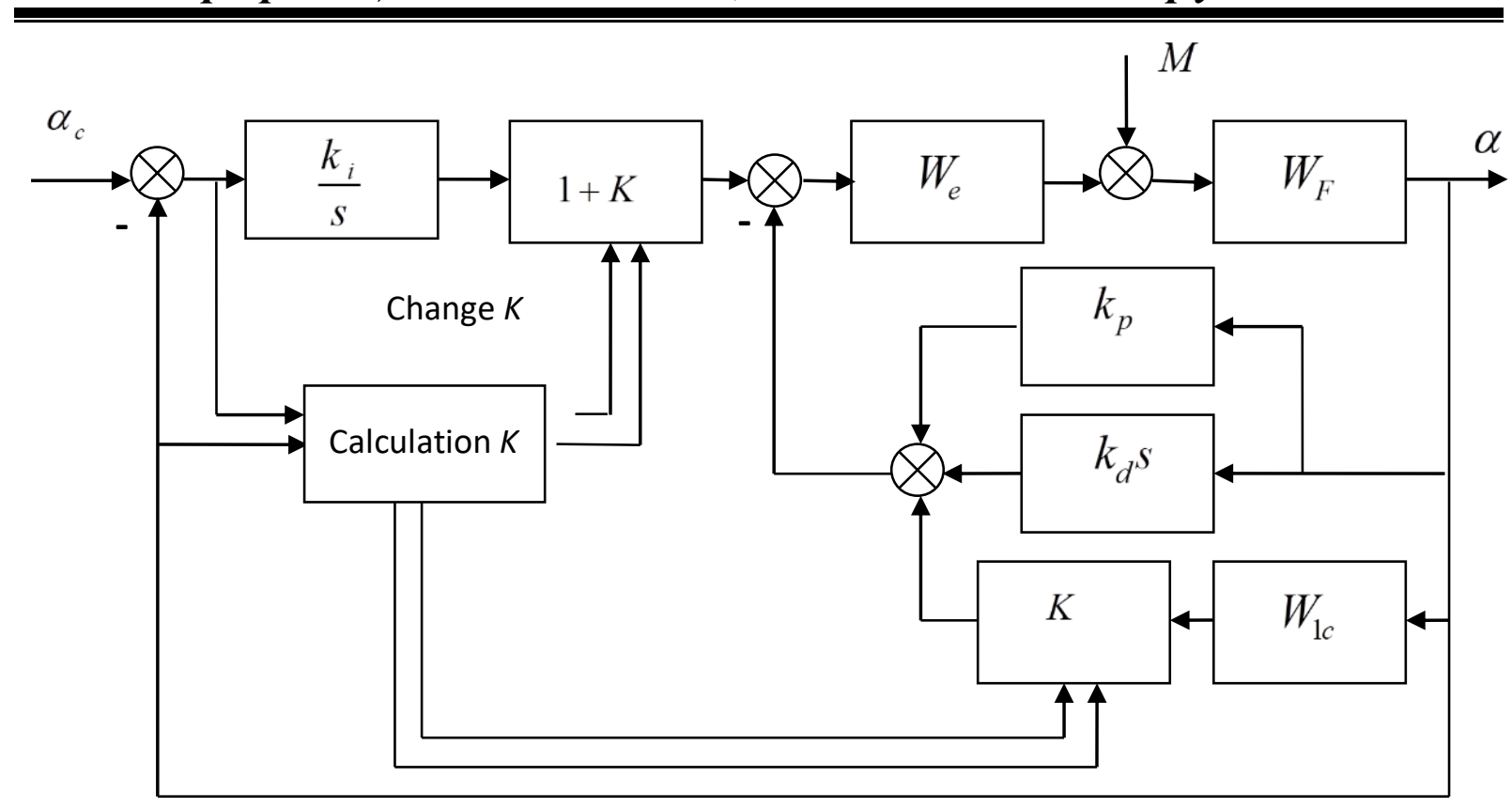

Fig. 6. Equivalent structural scheme of the system

Formation of the coefficient $\boldsymbol{K}$ from the multicopter deflection angle

Let us accept

$$
K_{i}=\left\{\begin{array}{c}
0, \text { if } \varepsilon_{\alpha i}<\alpha_{d p} K_{n m} ; \\
c\left|\varepsilon_{\alpha i}\right|, \text { if } \varepsilon_{\alpha i} \geq \alpha_{d p} K_{n m} \\
K_{i-1}, \text { if } c\left|\varepsilon_{\alpha i}\right|<K_{i-1},
\end{array}\right.
$$

where $\alpha_{d p}$ - the control system error limit, $\varepsilon_{\alpha}$ - the control error, $c$ - the constant that determines the change rate of the coefficient $K, K_{n m} \alpha_{d p}$ - the $\varepsilon_{\alpha}$ lower limit from which the algorithm begins to work.

The system limits the maximum value of $K: K=K_{\max }$, if $K>K_{d p}$.

The results of the control system reaction simulation with the specified algorithm for $\alpha_{d p}=5$ grad for perturbation of different magnitudes (fig. 7) are shown in fig. 8. It is seen that the system of formation of the feedback coefficient $K$ significantly reduces the external impact on the multicopter. In fig. 9 the graph of the coefficient $K$ change is shown. 
$\begin{array}{lllllllll}\boldsymbol{K} & \boldsymbol{e} & \boldsymbol{p} & \boldsymbol{y} & \boldsymbol{\theta} & \boldsymbol{a} & \boldsymbol{H} & \boldsymbol{H} & \boldsymbol{A}\end{array}$

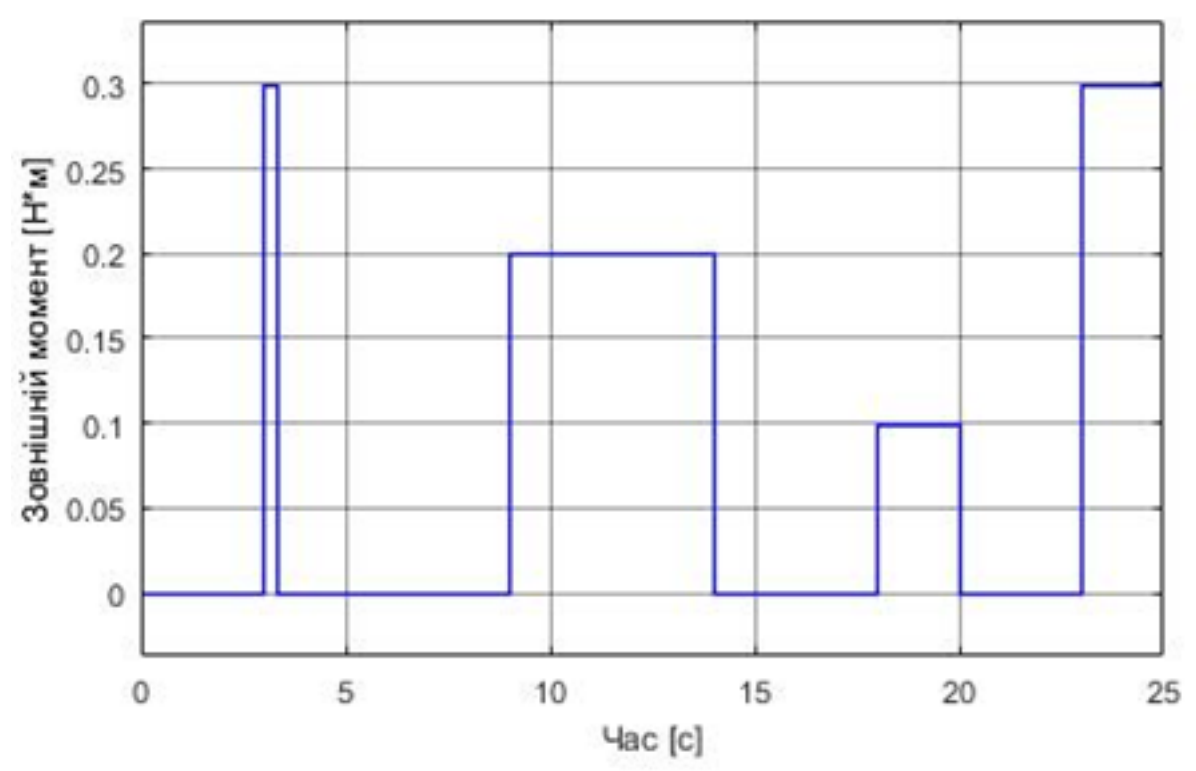

Fig. 7. External perturbations of multicopter

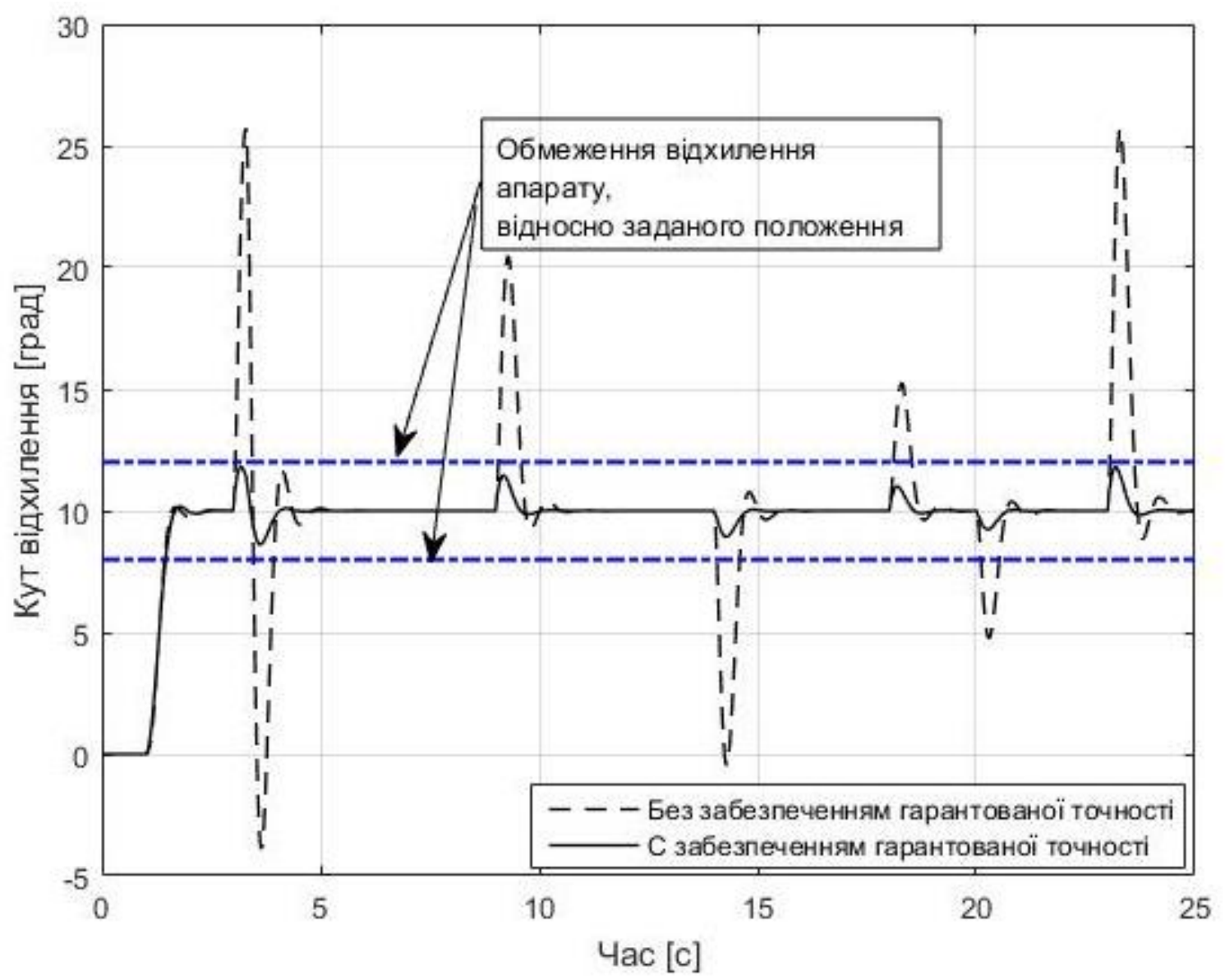

Fig. 8. Reaction to external perturbation 


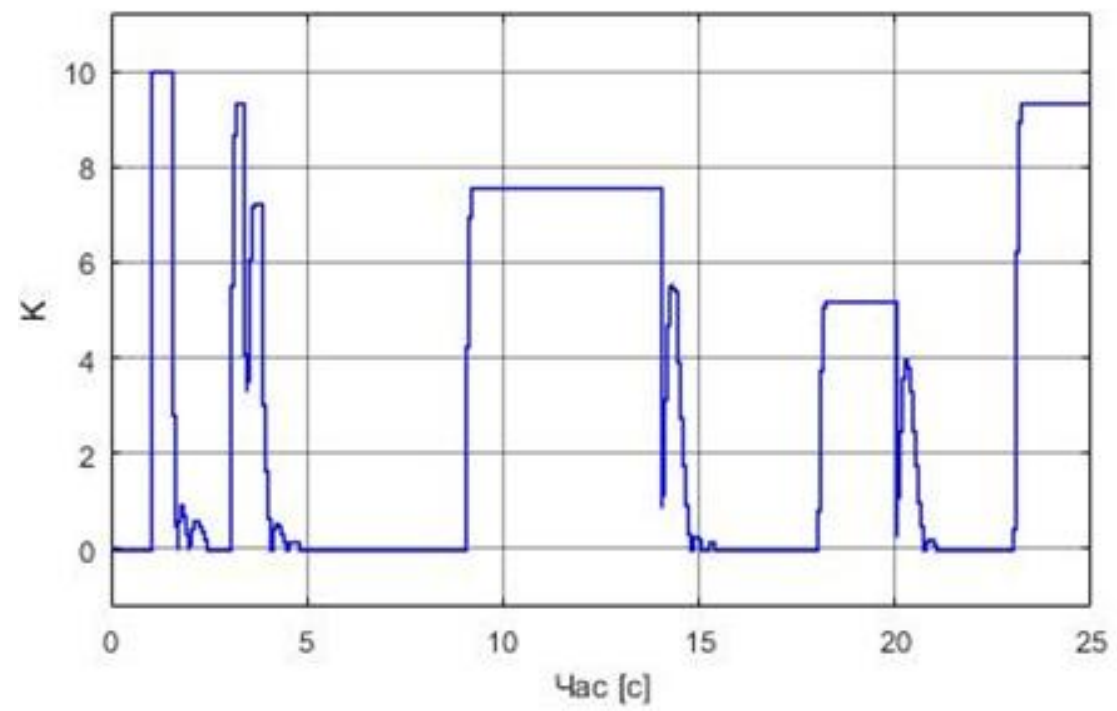

Fig. 9. Chart of coefficient $K$ changes

\section{Conclusion}

The proposed and developed control law of the multicopter angular positions and the block diagram of the regulator provide a given accuracy of the apparatus angular position under the influence of uncertain disturbances, without changing the quality of control.

\section{References}

1. Nebylov A. V. Guaranteed precision control. - M .: Science, 1998.-304 p.

2. Makarov N. N., Makarova N. N. Synthesis of the regulator by the method of guaranteed accuracy // Bulletin of TSU.- Computing. Automation. Control. 2000. - V. 2. - № 3. P. 41-52.

3. Nikiforov V. O., Slita O. V., Ushakov A. V. Intelligent control in conditions of uncertainty // Textbook. - СПб: СПбГУ ИТМО.- 2009. - 232 p.

4. Nikiforov V. O. Adaptive and robust control with compensation of perturbations.- СПб.:Science, 2003.-282 p.

5. Zbrutsky A. V., Prach A.A. Provision of software control accuracy in arbitrary perturbations // Control systems, navigation and communications.2007. - №3 - P. 41 - 46.

6. Zbrutsky A. V., Mischuk A. S. Adaptive control algorithm with the given accuracy at indeterminate external perturbations // Information systems, mechanics and control. -2014.-№ 10.- P. 170-177.

7. Kuzovkov N. T. Aircraft Stabilization Systems // M., High School.- 1976.304 p. 